\title{
APLICAÇÃO DE PROGRAMAÇÃO LINEAR EM UM PROBLEMA DE ROTEIRIZAÇÃO COM RASTREABILIDADE DO ROTEIRO VIA TECNOLOGIA RFID
}

\author{
Samuel Bloch da Silva. M.Sc. ${ }^{1}$, Prof. Dr. Anderson Ribeiro Correia ${ }^{2}$ \\ ${ }^{1}$ Instituto Tecnológico de Aeronáutica - ITA \\ São José dos Campos , São Paulo, Brasil \\ samuel@ita.br \\ ${ }^{2}$ Instituto Tecnológico de Aeronáutica - ITA \\ São José dos Campos , São Paulo, Brasil \\ correia@ita.br
}

\begin{abstract}
Resumo: O objetivo principal deste artigo é endereçar tópicos de gerenciamento baseado em ferramentas fundamentais como matemática e pesquisa operacional, em consonância com tecnologias como a identificação via rádio frequência RFID
\end{abstract}

Palavras chave: RFID, Programação Linear, Roteirização, Rastreabilidade

Abstract: The main purpose of this paper is to address management issues with tools from foundational fields such as mathematics and operations research, as well as cross-functional, multidisciplinary research like Radio Frequency Identification Technology

Keywords: RFID , Linear Programming, Routing, Track

\section{INTRODUÇÃO}

Management Science é uma subárea dentro da Pesquisa Operacional (PO) cujo estudo integra computadores, estatística e matemática para resolver problemas reais do mundo dos negócios sob três objetivos principais segundo Lachtermacher (1) :

- Converter dados em informações significativas

- Apoiar o processo de tomada de decisão

- Criar sistemas computacionais úteis aos usuários não técnicos

Ou seja , Pesquisa Operacional (PO) está intimamente ligada ao processo de tomada de decisão das empresa que a utilizam, principalmente no que tange ao levantamento de um problema ou identificação de uma oportunidade com as devidas linhas de ações . Basicamente a modelagem de um problema ou oportunidade se dará através de (1)

- $\quad$ Modelos Físicos

- Modelos Análogos

- Modelos Matemáticos ou Simbólicos

Os modelos matemáticos são os mais utilizados em análises gerenciais que envolvem problemas / oportunidades de distribuição de recursos limitados entre atividades que estão competindo pelo mesmo recurso (2) . Dentro da programação matemática existem ainda uma subdivisão que dependerá do tipo das funções utilizadas nas funções-objetivo e restrições (1):

"Programação Linear - Programação Matemática em que todas as funções-objetivo e restrições são representadas por funções lineares 
Programação Não-Linear - Programação Matemática em que pelo menos uma das funções-objetivo e/ou restrições são representadas por funções não-lineares"

\section{CONCEITUAÇÃO PRELIMINAR}

Como mencionado anteriormente a programação linear é uma técnica matemática que tem por objetivo encontrar a melhor solução para problemas que tenham seus modelos representados por expressões lineares (3). Sob vários aspectos a Programação Linear é uma das técnicas da Pesquisa Operacional mais utilizadas em se tratando de problemas de otimização. Neste sentido sua modelagem busca a distribuição eficiente de recursos limitados para atender um determinado objetivo, em geral, maximizar lucros ou minimizar custos (3).

Dentro da proposta de roteirização, a programação linear neste caso consistiria na maximização ou minimização de uma função linear, denominada função-objetivo relacionada ao Custo Total de Frete , respeitando-se um sistema linear de igualdades ou desigualdades que recebem o nome de restrições do modelo. Simplificadamente a minimização do "custo total de frete" poderia ser representada por:

$$
M I N Z=\sum_{\text {allarcs }} X_{i j}
$$

Onde,

$$
X_{i j j} \text { - quilometragem entre o nó "i" e "j" }
$$

Ou seja, com a otimização estaria relacionada a seleção da menor distância entre os demandantes do transporte, o que na prática impacta os custos às empresas pertencentes ao cluster de fornecimento. Concomitantemente, a expressão acima não estaria completa sem o devido tratamento das restrições. Conceitualmente restrição é aquilo que impede um melhor desempenho de um sistema e representa normalmente limitações de recursos disponíveis (capital, mão-de-obra, recursos minerais ou fatores de produção) ou exigências e condições que devem ser cumpridas no problema (3). Dentro do contexto proposto, as restrições estariam ligadas à definição das melhores rotas de transporte em função das menores distâncias a serem percorridas maximizando a função-objetivo proposta. Surge então a tecnologia de RFID monitorando o cumprimento do que foi roteirizado, a fim de se conhecer os desvios inerentes ou não do processo de transporte. Ou seja , a tecnologia funcionará como "coletor" de eventos gerando posteriormente gráficos de controle estatístico , a fim de se analisar as causas dos desvios conforme abordado por Montgomery (4) :

Em qualquer processo ..., independente de quão bem planejado ou cuidadosamente mantido ele seja, uma certa quantidade de variabilidade inerente ou natural sempre existirá . Essa variabilidade natural ou "ruído de fundo" é o efeito cumulativo de muitas pequenas causas, essencialmente inevitáveis.

Na prática espera-se conhecer os desvios gerados por quem os opera, cujas causas estão diretamente relacionadas ao cumprimento do que foi planejado via Programação Linear. Isto está muito além das quebras mecânicas ou problemas com engarrafamentos, cujas causas são inerentes ao processo de transportar. Tal variabilidade é, geralmente, muito grande quando comparada com o ruído de fundo, e representa usualmente um nível inaceitável do desempenho do processo . O monitoramento da roteirização através desta tecnologia permitirá entender tanto as causas aleatórias, mas principalmente as causas atribuíveis que deterioram o 
performance de todo o sistema de transporte das empresas envolvidas, penalizando a funçãoobjetivo prevista na Programação Linear .

Diante do exposto, o presente artigo se concentrará apenas na aplicação do modelo de Programação Matemática Linear na solução de roteirização em uma cadeia de fornecedores de subcontrato aeronáutico dentro do estado de São Paulo. Consonante com a programação linear, o estudo prevê a utilização da tecnologia de identificação via RFID no sentido de se "rastrear" no ambiente físico o que foi roteirizado matematicamente.

\section{ESTUDO DE CASO}

O Estado de São Paulo concentra o maior polo aeroespacial da América Latina. Entre as três maiores do mundo, a Empresa Brasileira de Aeronáutica (Embraer) e outras companhias que atuam no setor desenvolvem no Estado seus processos e produtos para os segmentos de aviação comercial e executiva, além de soluções integradas para defesa e segurança. De acordo com a Relação Anual de Informações Sociais (Rais) do Ministério do Trabalho e Emprego (MTE), o Brasil conta com 136 estabelecimentos instalados para fabricação de aeronaves. Desses, 99 estão em São Paulo (5). Ou seja a industria aeronáutica dentro do Estado de São Paulo caracteriza ponto focal de aplicação de métodos e tecnologias, principalmente pelo valor agregado e custos dos componentes envolvidos na cadeia produtiva. A seguir o estudo de caso será caracterizando com base no método e tecnologia proposta pelo artigo.

\subsection{ROTEIRIZADOR VIA PROGRAMAÇÃO LINEAR}

Além do que foi abordado anteriormente, há ainda uma outra classificação quanto ao nível de incerteza existente em relação as variáveis de decisão do modelo . Isto pode ser classificado como Modelos Determinísticos e Modelos Probabilísticos (12). Os Modelos Determinísticos consideram que todas as informações são assumidas como conhecidas, ou seja sem incertezas. Já os Modelos Probabilísticos apresentam uma ou mais variáveis de decisão não conhecidas com certeza. No estudo de caso proposto , a premissa assumida foi determinística na construção do modelo de roteirização, a saber :

\subsubsection{Distâncias}

As distâncias entre os fornecedores de subcontrato e um potencial centro de distribuição de matéria prima é conhecida, variando apenas o sequenciamento das entregas com base nas demandas no horizonte de tempo . A figura 1 apresenta as distâncias mapeadas via Google Earth: 


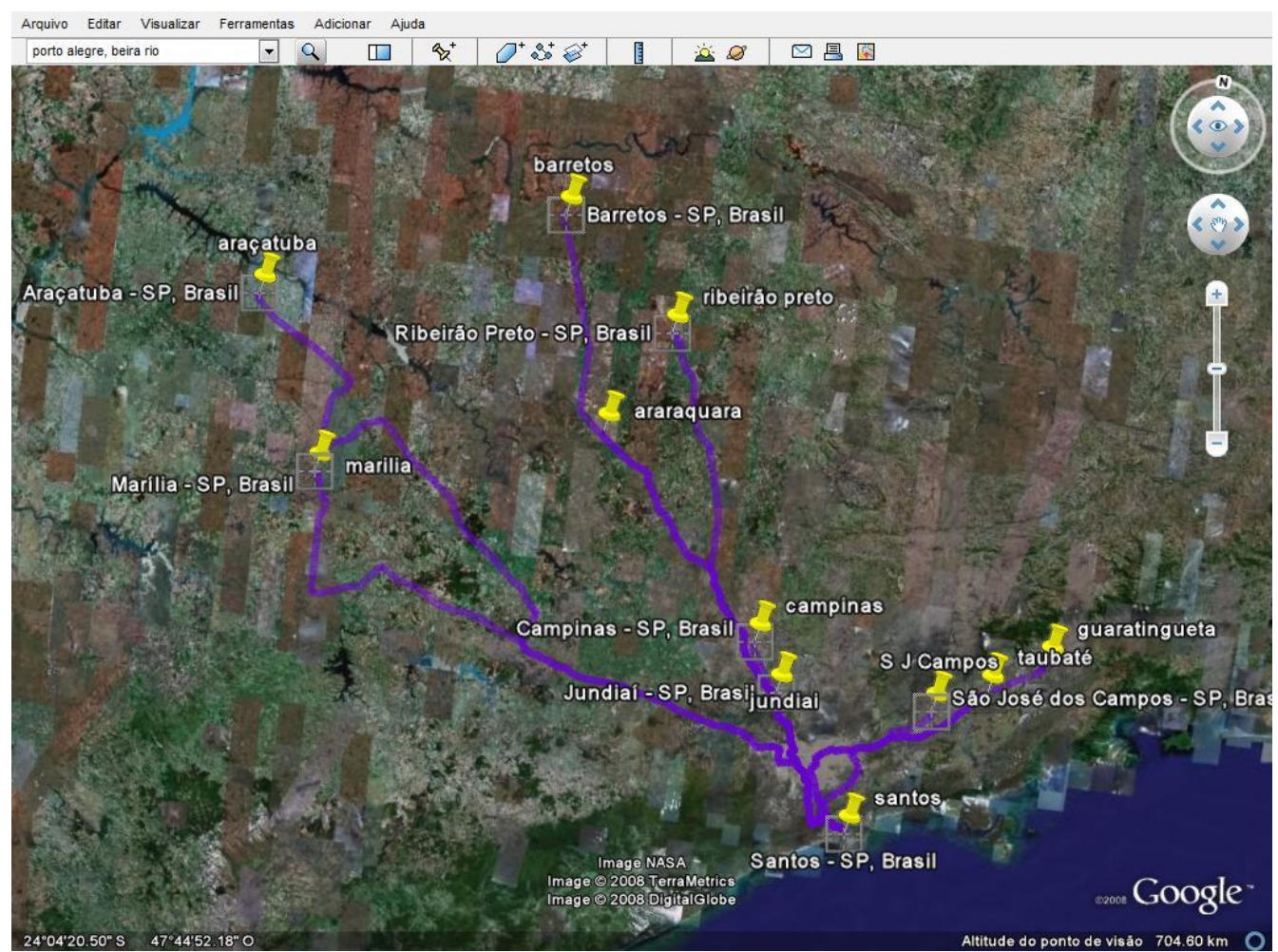

Figura 1- Mapeamento das Distância via Google Earth

Teoricamente as matérias primas importadas serão desembarcadas no porto de Santos e transportados diretamente a um centro de distribuição em Araraquara, que se encarregaria de abastecer os fornecedores existentes em Marília, Araçatuba, Ribeirão Preto e Barretos. Estas empresas subcontratadas sem reportam a um integrador aeronáutico em São José dos Campos, o qual não foi contemplado no presente artigo. Traduzindo a Figura 1 e suas distâncias em um diagrama de rede teremos a Figura 2 :

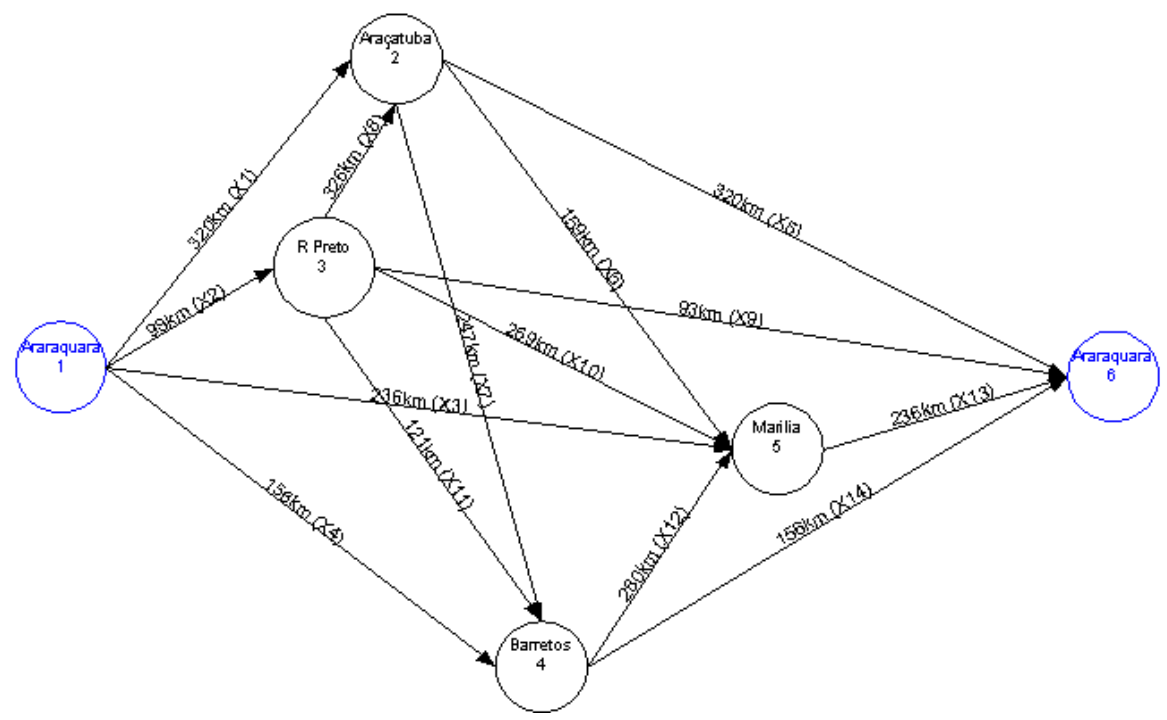

Figura 2 - Diagrama de Rede dos Fornecedores do Estados de São Paulo 


\subsubsection{Roteirização}

A roteirização será diária mediante composição da demanda dos fornecedores subcontratados por matérias primas específicas e efetivada mediante veículos próprios do centro de distribuição, obedecendo as seguintes variáveis de decisão:

$$
\begin{aligned}
& \text { X1 - de Araraquara (nó 1) para Araçatuba (nó 2) } \\
& \text { X2 - de Araraquara (nó 1) para R. Preto(nó 3) } \\
& \text { X3 - de Araraquara (nó 1) para Marília (nó 5) } \\
& \text { X4 - de Araraquara (nó 1) para Barretos (nó 4) } \\
& \text { X5 - de Araçatuba (nó 2) para Araraquara (nó 6) } \\
& \text { X6 - de Araçatuba (nó 2) para Marília (nó 5) } \\
& \text { X7 - de Araçatuba (nó 2) para Barretos (nó 4) } \\
& \text { X8 - de R. Preto (nó 3) para Araçatuba (nó 2) } \\
& \text { X9 - de R. Preto (nó 3) para Araraquara (nó 6) } \\
& \text { X10 - de R. Preto (nó 3) para Marília (nó 5) } \\
& \text { X11 - de R. Preto (nó 3) para Barretos (nó 4) } \\
& \text { X12 - de Barretos (nó 4) para Marília ( nó 5) } \\
& \text { X13 - de Marília (nó 5) para Araraquara (nó 6) } \\
& \text { X14 - de Barretos (nó 4) para Araraquara (nó 6). }
\end{aligned}
$$

\subsubsection{Sistema GPS Desligado}

O modelo teórico proposto funcionará independente do sistema GPS tradicional, onde o veículo será identificado com um tag passivo e reportará os eventos via portal RFID a serem instalados nas portarias do centro de distribuição e nos fornecedores à um sistema supervisório central. Isto significa que as empresas participantes desta sistemática teriam controle sobre a informação, não dependendo da exportação de dados dos fornecedores de serviço GPS.

\subsubsection{Definição da Função Objetivo}

Partindo-se inicialmente de que a minimização do custo com frete passa pela racionalização das distâncias a serem percorridas, segue a função-objetivo proposta:

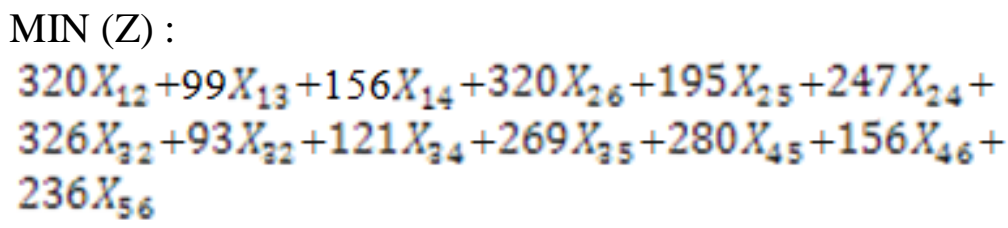

O termo " $320 \mathrm{X}_{12}$ " dentro da função-objetivo proposta reflete que cada embarque com origem em Araraquara ( nó 1) para Araçatuba ( nó 2 ) representa uma quilometragem de 320 $\mathrm{km}$. O mesmo racional valerá para os demais componentes da expressão conforme variáveis abordadas no tópico 3.1.2 .

No diagrama de rede proposto na Figura 2 , o sistema permitirá que o caminhão saia do centro de distribuição (CD) em Araraquara e faça a melhor rota de entrega entre aos fornecedores. Ou seja, o caminhão ficará vazio apenas na última entrega, retornando o mesmo ao CD. 


\subsubsection{Distâncias}

A maioria dos problemas relacionados a transporte e logística podem ser categorizados como problemas de fluxos em rede (8). Considerando a função-objetivo proposta com as características apresentadas na Figura 2, seguem as seguintes restrições ao fluxo:

$$
\begin{aligned}
& -\left(X_{12}+X_{13}+X_{14}\right)=-1 \\
& X_{12}-X_{26}-X_{25}-X_{24}=0 \\
& X_{13}-X_{32}-X_{36}-X_{35}-X_{34}=0 \\
& X_{14}-X_{34}-X_{24}-X_{45}-X_{46}=0 \\
& X_{25}-X_{35}-X_{15}-X_{45}-X_{56}=0 \\
& X_{26}+X_{36}+X_{56}+X_{46}=1
\end{aligned}
$$

\subsubsection{Solução envolvendo Demanda, Variáveis, Função Objetivo e Restrições com a função Solver do Excel}

Dentre os vários softwares existentes, a opção foi por modelar a solução no Microsoft Excel, através da função "solver" conforme apresentado na Tabela 1:

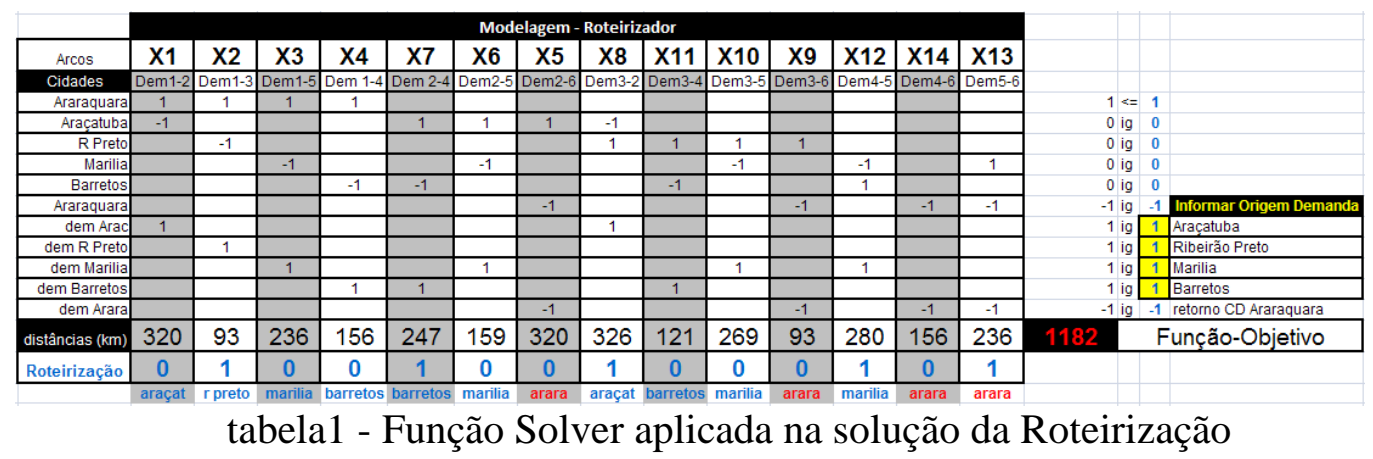

O resultado obtido na Tabela 1 representa as iterações processadas pela função solver para entregas simuladas em R. Preto, Araçatuba, Barretos e Marília. Consequentemente para as demandas assinaladas no período, a tabela apresenta a rota com o menor de custo frete em função dos quilômetros a serem rodados. Representando graficamente o resultado da Tabela 1 , o planejamento das entregas nos fornecedores pelo menor caminho seria procedido conforme figura 3:

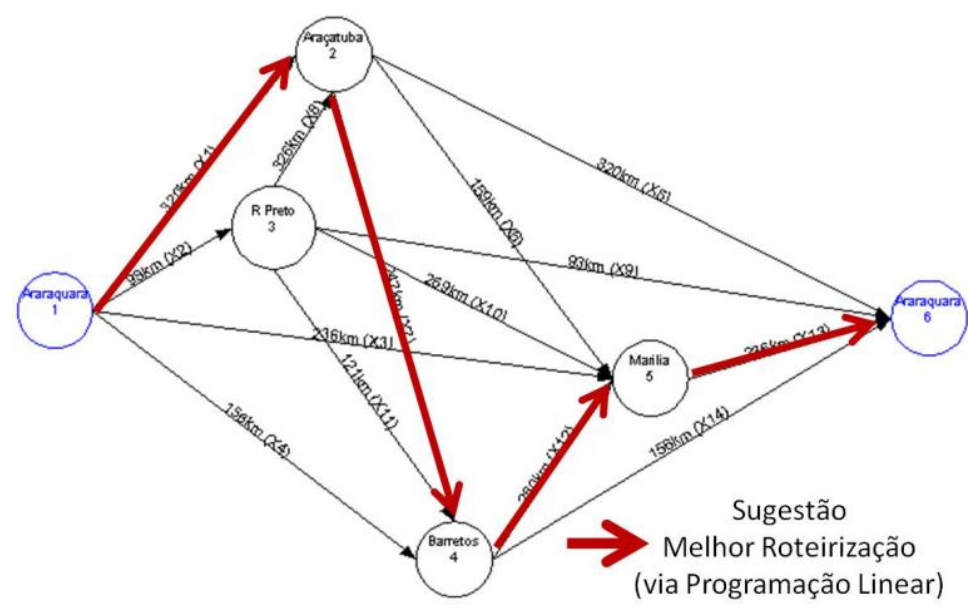

figura 3 - solução gráfica para a roteirização 
A fig. 3 sugere um plano de trabalho específico para o motorista do veículo, o qual será variável a cada dia e/ou semana em função da sumarização das demandas e quilometragem possível de ser cumprida. Além da roteirização sugerida envolvendo a otimização das distâncias, o modelo desenvolvido poderá ser útil futuramente em simulações de fretes em veículos alternativos ou ampliação da base de fornecedores subcontratados.

A seguir serão abordados aspectos da tecnologia RFID que complementam a proposta do presente artigo.

\subsection{APLICAÇÃo DA TECNOLOGIA RFID NO CONTROLE DA ROTEIRIZAÇÃo}

Até o momento tudo o que foi apresentado remonta o lado determinístico do processo de transporte envolvido no hipotético estudo de caso. Na prática nem sempre o que foi planejado acontece dentro das expectativas . Conforme Montgomery , existem "causas atribuíveis" que não fazem parte do processo , mas que geram resultados inaceitáveis de desempenho do mesmo (4).

\section{Para Rodrigues(13)}

A variabilidade de um processo é atribuída a dois tipos de causas: as comuns e as especiais. As causas comuns são aspectos normais ou pertinentes ao processo e estão associadas ao desenho, estruturas e atores do processo. As causas especiais são imprevisíveis e esporádicas, causam pontualmente ou momentaneamente grandes variações e são difíceis de serem previstas já que estão associadas a parâmetros não controláveis do processo .

O que o presente artigo está propondo nesta fase é a possibilidade de se utilizar a tecnologia RFID na busca destas causa especiais, além de popular uma base de dados orientada a geração de métricas ao processo decisório gerencial; bem como covalidar a roteirização disponibilizada via programação linear .

Segundo Silva \& Batocchio (6) :

Tecnicamente falando, as tecnologias de auto-identificação desempenham o mesmo papel na aquisição automática dos dados de um processo qualquer. Comparando-se os vários sistemas de identificação, percebemos que o sistema baseado em radio freqüência leva vantagem sobre os demais pelo fato de independer da vontade humana para efetuar os registros ...

Sob o ponto de vista técnico-operacional cada tecnologia tem suas vantagens e desvantagens . Vários estudos apontam para a tecnologia de RFID em função da potencial integração com os projetos outros projetos no Brasil e exterior. Conforme os pesquisadores da Universidade de Saint Gallen na Suiça, a tecnologia RFID forneceria condições ideais à automação de várias atividades manuais existentes nos processos internos e externos das empresas, pelo fato da tecnologia aproximar o mundo digital do mundo real sem a necessidade da interferência humana direta (10). Comparativamente o sistema baseado em radio frequência leva vantagem, em especial sobre o código de barras, pelo fato de funcionar com base em emissões de ondas eletromagnéticas, e tudo o que estiver identificado por um tag (pessoas, produtos, equipamentos etc.) dentro do raio de ação das ondas eletromagnéticas 
geradas pelo conjunto antena/reader será registrado e disponibilizado automaticamente aos envolvidos internamente e externamente em tempo real. Isso significa que quanto maior for a área de cobertura gerada pelas antenas, maior será a superfície ativa entre as unidades de negócio, no sentido de capturar e disponibilizar os movimentos dos processos monitorados via RFID (6). Segundo Brintrup, Roberts, Astle (11), usar a tecnologia de RFID para eliminar a necessidade de se lançar documentos, ordens de produção e outras informações relevantes nos sistemas produtivos, ajudará as empresas a evitarem desperdícios com movimentações desnecessárias das pessoas e erros decorrentes do processo manual de coleta dos dados. Para Fleisch (9), o futuro será a "internet das coisas", onde será possível conectar qualquer coisa material de nosso mundo a internet . Segundo o mesmo autor a tecnologia RFID funcionará como uma das peças chaves neste contexto. Dentro do escopo proposto trataremos a tecnologia RFID de forma genérica , não cabendo a este artigo apresentar as diferentes variações quanto seu funcionamento e características operacionais. Por outro lado , um estudo mais profundo precisará ser executado a fim de responder aos questionamentos técnicos referentes ao caso proposto .

Questões técnicas a parte , uma infraestrutura inicial precisará ser implantada no CD , fornecedores e nos veículos para que os eventos gerados pelos tags sejam capturados e os dados analisados contra a roteirização via Programação Linear no Excel . Isto significa que além dos tags afixados nos caminhões, teremos portais de entrada e saída em cada nó da rede de transporte conforme sugerido pela Figura 4:

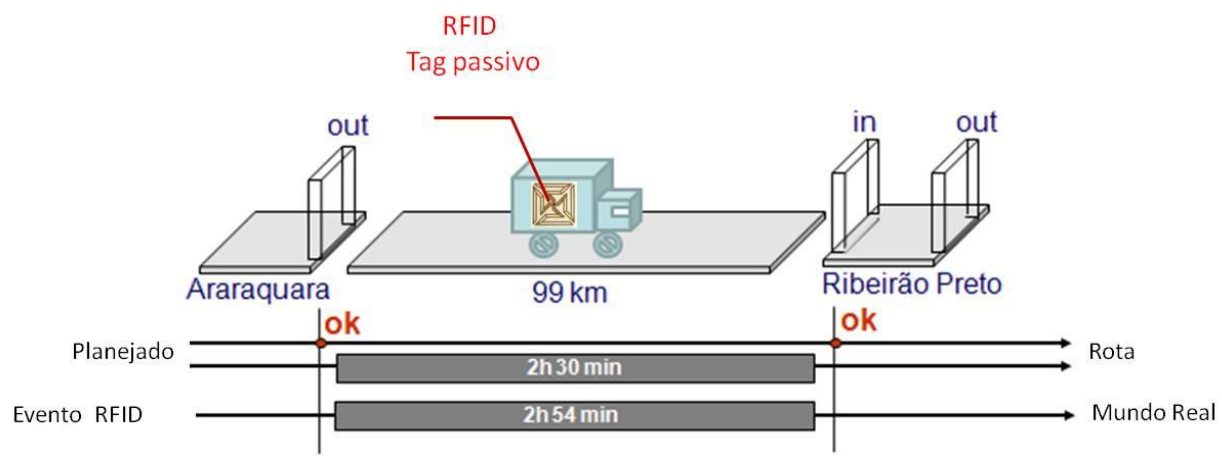

figura 4 - Controle de Execução da Rota

No exemplo da Figura 4 o sistema apontaria o tempo de deslocamento entre os pontos Araraquara - Ribeirão Preto , além de informar ao roteirizador que a rota foi feita conforme planejado. A modelagem permitirá uma série de análises para cada "arco" e "nó" da rota, bem como aprimorar o planejamento logístico com métricas realistas. Ou seja, mesmo que os pontos de controle se situem entre os limites estabelecidos, se eles se comportarem de maneira sistemática ou não aleatória , isto poderá ser um indicativo de que alguma coisa no processo de transporte está fora de controle . Tipicamente as coletas efetuadas pelo RFID irão compor um Gráfico de Controle da rota de transporte, conforme proposto na Figura 5: 


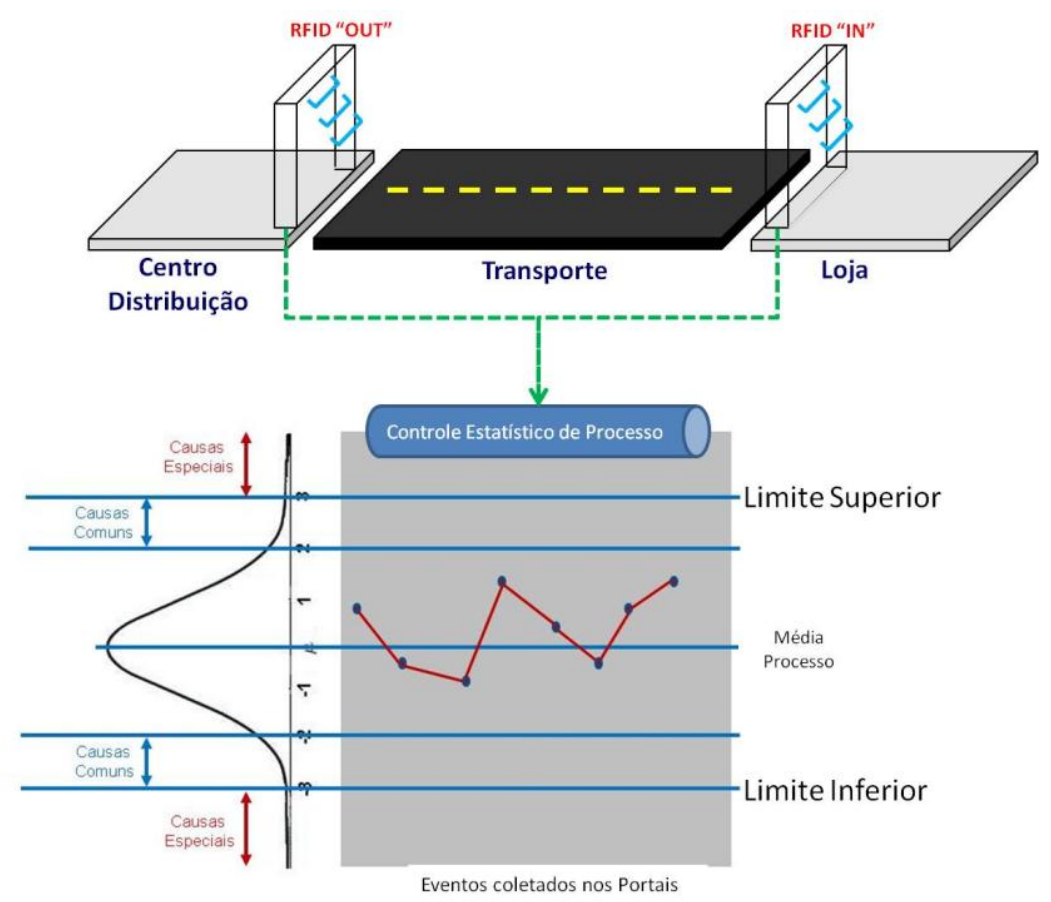

figura 5 - Gráfico de Controle da Rota de Transporte

O uso mais importante do gráfico de controle seria para melhorar o processo em questão, que segundo Montgomery permitirá a criação de um Plano de Ação para Fora de Controle (PAFC).

$O$ PAFC consiste em pontos de vistoria, que são potenciais causas atribuíveis, $e$ finalizadores , que são as ações empreendidas para resolver a condição fora de controle . (4)

Neste contexto vale lembrar que a maior parte dos processos nas empresas não operam em uma distribuição normal, produzindo assim grandes descontentamentos operacionais aos clientes em função da métricas não cumpridas.

Segundo Simchi-Levi e Kaminsky (7), os indicadores da cadeia logística afetam a capacidade de prover valor ao cliente em especial na dimensão disponibilidade de produtos.

Muitas empresas consideram este indicador tão importante nos mercados que atuam que investem muito em sistemas de apoio à decisão capazes de avaliar as datas de entrega com acuracidade, analisando a informação em toda a cadeia de suprimentos. (7)

No artigo a preocupação com tais métricas é apresentado na Figura 5 , cujo futuro modelo resultará em sistema de apoio a gerência, operadores logísticos e engenheiros no sentido de eliminar mais facilmente as causas atribuíveis deste processo. Além do sistema de medição, a visão poderá interessar à empresas que operem com terceirizados mas que tenham dificuldades em acompanhar o nível de serviço prestado. Na prática nem sempre é muito fácil encontrar meios seguros de se validar a execução do planejado, até porque a maior parte dos sistemas baseados em GPS não fornecem este tipo de visão.

Neste sentido, a nova representação da cadeia logística dos fornecedores de subcontrato aeronáutico do Estado de São Paulo integrando o roteirizador com a monitoração da rota via RFID, poderia ser representado pela Figura 6 : 


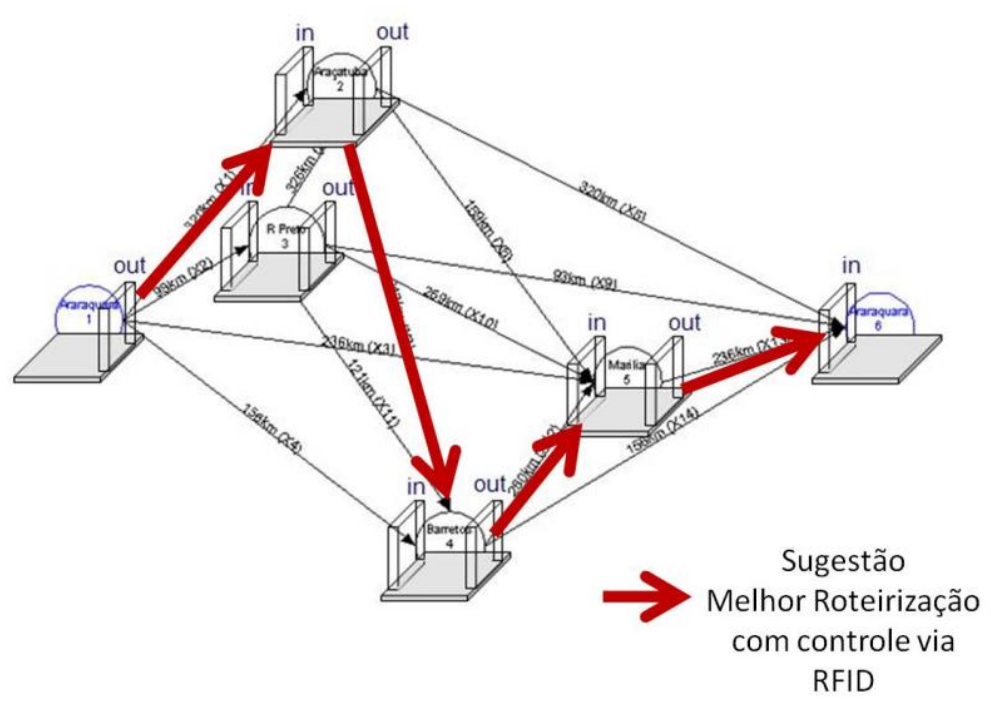

figura 6 - Representação da Cadeia Logística dos Fornecedores integrando o Roteirizador e a monitoração da Rota via RFID

\section{CONCLUSÃO E SUGESTÃO PARA FUTUROS TRABALHOS}

O presente trabalho não encerra a discussão deste assunto , mas propõem uma abordagem diferente do modelo tradicional baseado apenas em GPS, considerando outros projetos de âmbito nacional em desenvolvimento. Esperamos fomentar a aplicação da tecnologia de RFID integrada com a programação linear, permitindo assim que diferentes aplicações possam ser estudadas pela comunidade empresarial e acadêmica . Como sugestão para próximos trabalhos, sugerimos a análise econômica do modelo proposto, considerando que uma vez instalada a infraestrutura necessária, a solução isenta a empresa de taxas mensais de manutenção dos sistemas GPS, bem custos decorrentes da implantação de sofisticados sistemas de gestão.

\section{REFERÊNCIAS}

(1) - LANCHTERMACHER , Gerson , Pesquisa Operacional na Tomada de Decisões , 3 ed. , Rio de Janeiro: Campus, 2007

(2) - VANDERBEI ,R. . Linear Programming - Foundations and Extensions . 3 ed , Springer. 2008

(3) - ANDERSON, D. R.; SWEENEY, D. J.; WILLIANS, T. A., Statistics for Business and Economics. Thompson, 2005.

(4) - MONTGOMERY , Douglas C. , Introdução ao Controle Estatístico da Qualidade , 4 ed. , Rio de Janeiro: LTC, 2001.

(5)- Investe São Paulo. Disponível em http://www.investe.sp.gov.br/setores-denegocios/aeroespacial-e-defesa/ . Acessado dia 20 de Abril de 2014 
(6)- SILVA , Samuel B. , BATOCCHIO , Antonio , O Processo de Track \& Trace na Cadeia Logística - Estudo de Caso : Setor Aeroespacial , UNESP , $3^{\circ}$ Workshop de Robótica Aplicada e Sistemas Colaborativos de Engenharia , Bauru, Dezembro 2008 .

(7) - SIMCHI-LEVI , David , KAMINISKY , Philip , SIMCHI-LEVI , Edith , Cadeia de Suprimentos , 1 ed., São Paulo: Bookman , 2003.

(8) - STRINGHER, Fabiano Gandini. Designação de Rotas para Frota Dedicada em uma Rede de Distribuição de Linha Branca. Dissertação de Mestrado - USP- 2004

(9) - FLEISCH, E. What is the Internet of Things ? An Economic Perspective . in White Paper Series. 2010: Auto-ID Labs, Zurich

(10) - ROUSSOS, G. Ubiquitous and Pervasive Commerce - New Frontiers for Electronic Business. Ed Springer, 2006

(11) - BRINTRUP, A.; ROBERTS P.; ASTLE M. Report: Metodology for Manufacturing Process Analysis for RFID Implementation, in BRIDGE Project White Paper Series. 2008: Auto-ID Labs, Cambridge, UK

(12) - ALTIOK, T., MELAMED, B.. Simulation Modeling and Analysis with Arena. Elsevier. 2007

(13) - RODRIGUES, M. V. Entendendo, Aprendendo, Desenvolvendo Qualidade Padrão. São Paulo. Ed Qualitymark, 2006 